\title{
Glacial terminations: Processes and feedbacks
}

\author{
Laurie Menviel', E. Capron ${ }^{2}$ and R. Ivanovic ${ }^{3}$
}

\author{
Online, 10 and 12 November 2020
}

\section{The PAGES-PMIP working group on} Quaternary Interglacials (QUIGS; pastglobalchanges.org/quigs) and INQUA PALCOM project (https://inqua.org/ commissions/palcom) on Terminations Five to Zero (TV-T0) held a virtual meeting on "Glacial terminations: processes and feedbacks" on 10 and 12 November 2020 (pastglobalchanges.org/calendar/2020/127 pages/2054). The meeting focused on the latest data and modeling results on the largest global climate changes of the Quaternary: the glacial-interglacial transitions, also referred to as terminations (Fig. 1).

This first QUIGS-PALCOM virtual meeting, which featured 33 talks, was attended by 70 scientists during both three-hour sessions. The sessions were scheduled so that scientists from across the world could attend at least one session at a convenient time, and the full meeting was recorded. Early-career researchers presented $75 \%$ of the talks, thus giving them a great opportunity to present their research to a large group of international experts.

Talks were mainly presented within breakout sessions focusing on (1) deglacial changes in the carbon cycle, (2) deglacial climate and ice-sheet dynamics, and (3) deglacial vegetation dynamics. Most presentations focused on $\mathrm{TI}(\sim 18-10$ thousand years before present; kyr BP) but some also presented results on TII ( 140-129 kyr BP) and on older terminations. A few presentations took the broader perspective of the last few million years.

Terminations $\mathrm{V}$ to I were interrupted by millennial-scale variability, with a weakening of the Atlantic Meridional Overturning
Circulation (AMOC; e.g. McManus et al. 2004; Cheng et al. 2016). New paleo proxy records from the Atlantic Ocean were presented, confirming the occurrence of significant $\mathrm{AMOC}$ weakening during $\mathrm{TI}$ and TII, while Southern Ocean ventilation was enhanced.

Latest modeling work on Termination I showed that coupled climate models, forced by deglacial ice-sheet evolution and associated meltwater routing, simulate the millennial-scale variability identified in paleorecords, but the simulated timing of these events is not correct. Hence, work remains to better understand the processes involved in the deglacial millennial-scale variability. In addition, some processes currently not taken into account in ice-sheet modeling, such as tidal amplitude and its impact on glacier drainage, could lead to rapid ice-stream deglaciation driven by instability processes.

Talks on deglacial changes in the carbon cycle highlighted the lack of consensus regarding the contribution of the different processes governing the deglacial atmospheric $\mathrm{CO}_{2}$ concentration increase, i.e. temperature, sea ice, iron fertilization, ocean circulation, and the terrestrial biosphere. Additional proxy records and modeling are still needed.

Discussions mainly focused on (1) the importance of feedbacks during terminations, and particularly the processes leading to the $\mathrm{CO}_{2}$ rise, given the role of the atmospheric $\mathrm{CO}_{2}$ increase in the deglacial temperature rise; and (2) the potential misrepresentation of deglacial ice-sheet history, including retention and routing of the meltwater into the

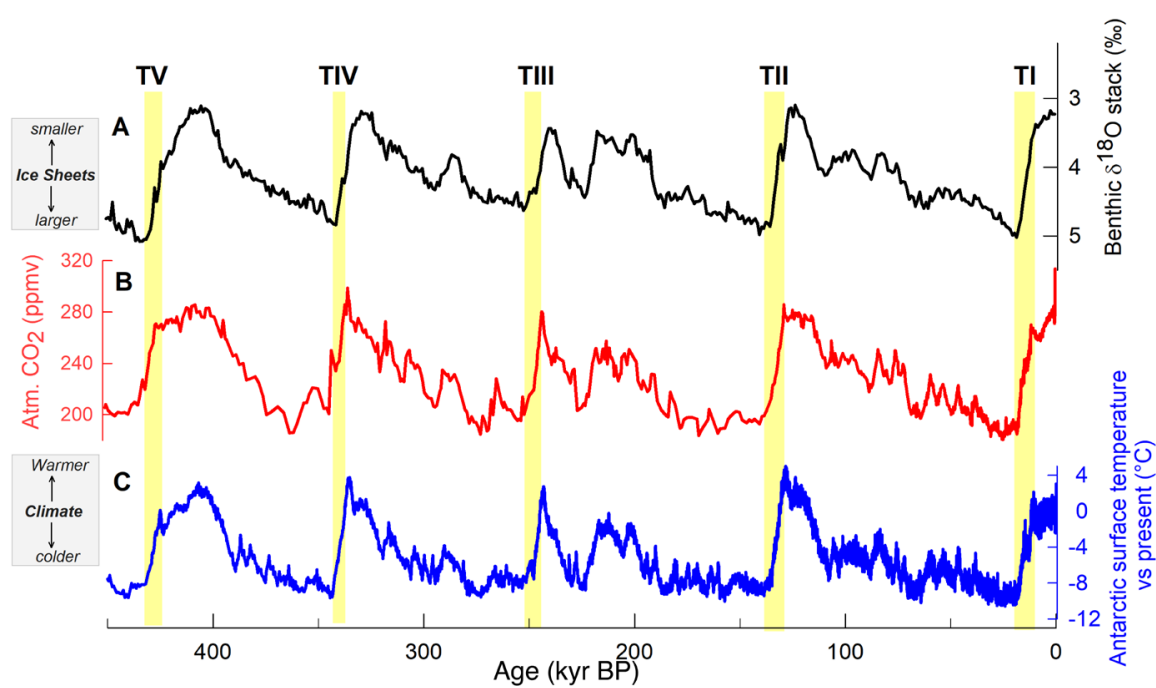

Figure 1: (A) Marine benthic foraminifera $\delta^{18} \mathrm{O}$ representing ice-sheet volume (Lisiecki and Raymo 2005); (B) Antarctic surface temperature reconstruction from the EPICA Dome C ice core (Jouzel et al. 2007); (C) composite atmospheric $\mathrm{CO}_{2}$ record from Antarctic ice cores (Bereiter et al. 2015). Vertical yellow bars highlight TV-TI. appropriate coastal regions, or inappropriate sensitivity of climate models to external forcings.

The meeting highlighted the need to improve our understanding of the deglacial sequence of events, including better constraints on the demise of glacial ice sheets and the associated meltwater routing, the drivers and role of millennial-scale variability, and the processes driving the measured atmospheric $\mathrm{CO}_{2}$ concentration increase. Additional paleorecords and modeling studies on TII-TV are needed, as they present additional case studies with different climate background and forcing and could thus provide constraints on deglacial processes and feedbacks. TIII ( 250 kyr BP) is a particularly interesting case, as changes during this interval are among the fastest over the past $800 \mathrm{kyr}$, and the millennial-scale dynamics appear to be different compared to other terminations (Cheng et al. 2016; Obrochta et al. 2014).

Robust chronologies for paleoclimatic records are essential in order to decipher the sequence of changes in climate, ice sheets, and the carbon cycle with respect to orbital forcing during glacial terminations. Although more challenging, this is especially true for TII-TV, where radiocarbon dating is not available. Such accurate chronologies are also crucial for robust model-data comparisons.

The joint in-person PAGES QUIGS-INQUA PALCOM TV-T0 workshop "Glacial terminations: processes and feedbacks" is currently scheduled for 21-23 September 2021 in Cassis, France (pastglobalchanges.org/ calendar/2021/127-pages/1992). It will focus on understanding whether the deglacial sequence of events influence the following interglacial. The causes for the observed differences between TI and TII will also be discussed in detail.

\section{AFFILIATIONS}

${ }^{1}$ Climate Change Research Centre, University of New South Wales, Sydney, Australia

${ }^{2}$ Université Grenoble Alpes, CNRS, IRD, IGE, France ${ }^{3}$ School of Earth and Environment, University of Leeds, UK

\section{CONTACT}

Laurie Menviel: I.menvie|@unsw.edu.au

\section{REFERENCES}

Bereiter B et al. (2015) Geophys Res Lett 42: 542-549

Cheng H et al. (2016) Nature 534: 640-645 Jouzel J et al. (2007) Science 317: 793-796 Lisiecki LE, Raymo ME (2005) Paleoceanography 20: PA1003

McManus JF et al. (2004) Nature 428: 834-837

Obrochta SP et al. (2014) Earth Planet Sci Lett 406: $198-212$ 